\title{
Synostosis in the Cervical Vertebrae: a Case Report
}

\author{
Denival Nascimento Vieira Júnior, ${ }^{1}$ Ardilles Juan Carlos Alves dos Santos, ${ }^{1}$ Kassia de Oliveira Gomes da Silva, ${ }^{2}$ João Antônio \\ Leal de Miranda, ${ }^{3}$ Katrine Bezerra Cavalcanti ${ }^{1}$
}

\begin{abstract}
${ }^{1}$ Campus Senador Helvídio Nunes de Barros, Federal University of Piauí - UFPI, Picos, PI, Brazil
${ }^{2}$ Department of Anatomy, Federal University of Pernambuco - UFPE, Recife, PE, Brazil

${ }^{3}$ Campus Professora Cinobelina Elvas, Federal University of Piauí - UFPI, Bom Jesus, PI, Brazil
\end{abstract}

Disclose and conflicts of interest: none to be declared by all authors

\begin{abstract}
Introduction: skeletal abnormalities in the cervical region are of great interest to anatomists and other health professionals. Fused cervical vertebrae (FCV) correspond to an important skeletal abnormality due to the fusion of two or more vertebrae. Case Report: owing to its clinical and embryological importance, herein, a case of cervical synostosis among a collection of anatomical pieces from a public university is reported. FCV were evidenced between the C5 and C6 vertebrae, with noticeable fusion of the vertebral bodies.

Conclusion: the study of normal morphology and understanding of anatomical changes in the spine, such as FCV, represent the preponderant stage for the training of health professionals.

Keywords: Anomaly; Block vertebrae; Fusion.
\end{abstract}

\section{Introduction}

The vertebral column extends from the skull to the apex of the coccyx and is composed of 33 vertebrae, which are divided into cervical, thoracic, lumbar, and sacral vertebrae. The cervical vertebrae are the smallest of the mobile vertebrae, located between the skull and thoracic vertebrae, thus constituting the skeleton of the neck ${ }^{1}$.

There are seven cervical vertebrae. The first $(\mathrm{C} 1$ : atlas), second (C2: axis), and seventh (C7: prominent vertebra) vertebrae have special characteristics and are considered atypical cervical vertebrae, while the third, fourth, fifth, and sixth (C3 to C6) vertebrae are almost identical to the general vertebral characteristics and termed typical cervical vertebrae ${ }^{2}$.

Like other bones, the vertebrae play a protective role, due to the passage of the spinal cord through the spinal canal, which is formed from the junctions of the vertebral foramina. In conjunction with the intervertebral discs, the vertebrae also promote cervical movement and lateral flexion and rotation ${ }^{3,4}$.

Skeletal abnormalities in the cervical region can result in severe neck pain, mobility changes, muscle weakness, and sensory deficits ${ }^{5}$. Among these skeletal anomalies, fused cervical vertebrae (FCV) stand out. In FCV, also known as vertebral fusion, vertebral synostosis, or block vertebrae, two vertebrae appear structurally and functionally as one due to the fusion of the vertebral bodies ${ }^{6}$. These fusions can be congenital or acquired and have clinical importance because of their ability to promote shortening of the spine in the cervical region, limitations in head and neck movements, bone malformations (scoliosis, kyphosis, torticollis), pain, weakness, and paralysis, among other symptoms ${ }^{7}$.

Despite great interest among anatomists, orthopedists, neurologists, and orthodontists 6,8,9, abnormalities in the cervical region are mostly detected incidentally during diagnostic imaging studies that are performed for other reasons and during dissections and necropsies in patients without a history of conditions without pain ${ }^{1}$. Herein, we report the findings of a case of synostosis in the cervical vertebrae among a university collection of anatomical pieces.

\section{Case Report}

When analyzing the collection of vertebrae from the university's anatomy laboratory, the presence of fusion of the fifth (C5) and sixth (C6) cervical vertebrae was observed (Figure 1). Given the case, the vertebrae were photographed from different aspects and their characteristics reported. In the upper aspect (Figure 2), the bodies of the two vertebrae were observed to have completely fused, and the transverse foramina remained preserved. In the posterior view (Figure 3), fusion between the transverse foramina and fusion of the lower joint process of C5 with the upper joint process of $\mathrm{C} 6$ were observed. It was also possible to observe the bifid spinous processes, which are characteristic of cervical vertebrae. Finally, disposition of the cervical region of the spine was observed (Figure 4), with the presence of FCV between C5 and C6 in its constitution. 


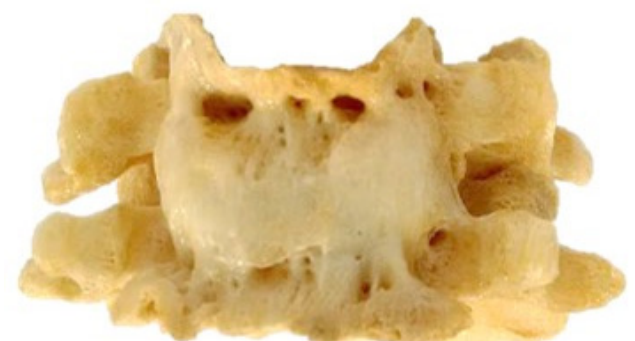

Figure 1. Anterior view of the FCV between $C 5$ and $C 6$. FCV, fused cervical vertebrae.

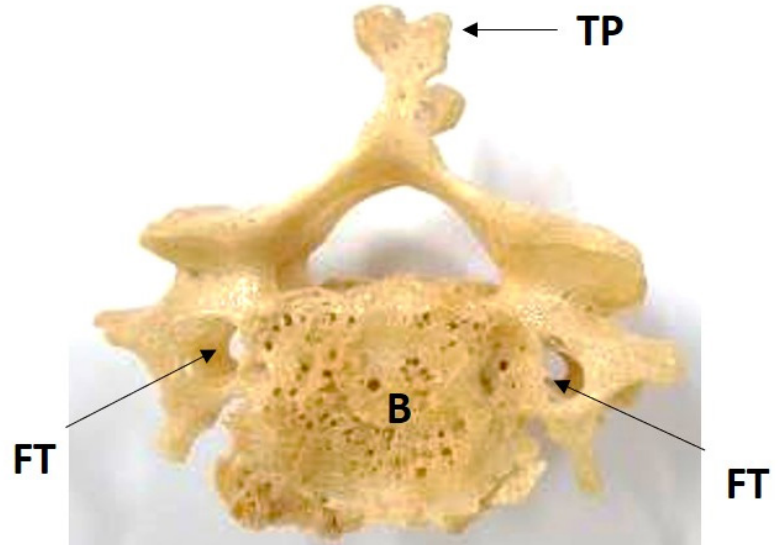

Figure 2. Superior view of the FCV between $\mathrm{C} 5$ and $\mathrm{C} 6$. FCV, fused cervical vertebrae; B: body; FT: foramen transversarium; TP: thorny process.

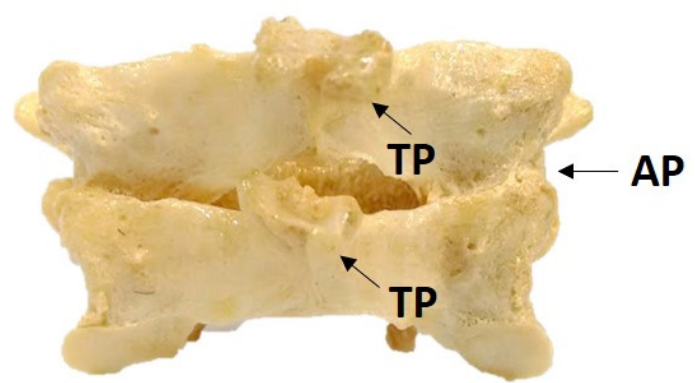

Figure 3. Posterior view of the FCV between $\mathrm{C} 5$ and $\mathrm{C} 6$. FCV, fused cervical vertebrae; TP: thorny process; AP: articular process.

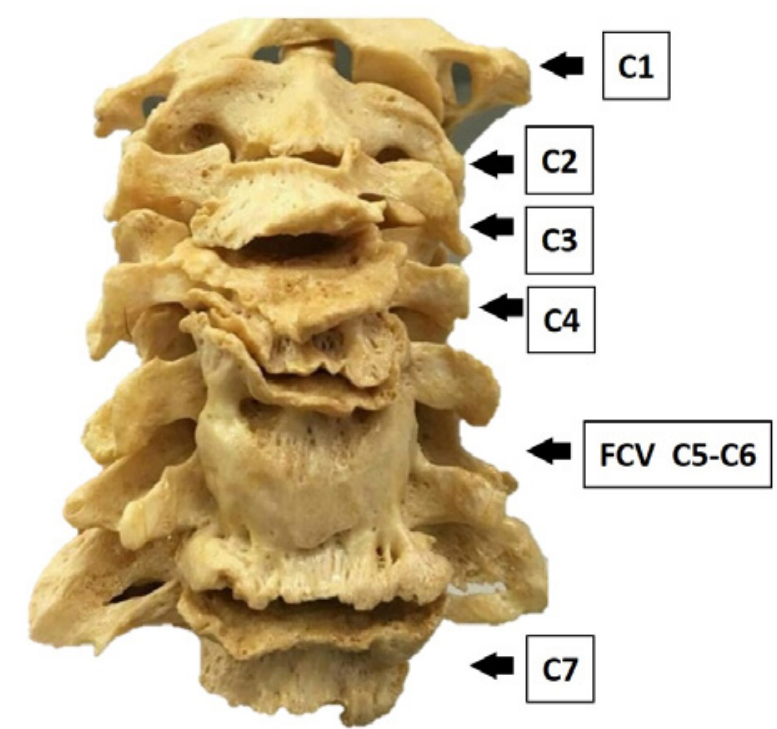

Figure 4. Anterior view of the cervical spine with the presence of FCV between C5 and C6. FCV, fused cervical vertebrae.

\section{Discussion}

FCV include faceted fusions, neural arch fusions, and block vertebrae. Block vertebrae have been used to describe the partial or complete fusion of two or more vertebrae, involving cartilage or bone ${ }^{2}$. In the present study, we observed the presence of FCV between $\mathrm{C} 5$ and $\mathrm{C} 6$. FCV are most commonly found in $\mathrm{C} 5-\mathrm{C} 6, \mathrm{C} 2-\mathrm{C} 3, \mathrm{C} 1-\mathrm{C} 2$, and $\mathrm{C} 6-\mathrm{C} 7$, in decreasing order of incidence ${ }^{10,11}$.

Regarding the etiology, FCV are associated with congenital causes, which are generally related to primary dorsal cord malformations, and acquired causes, which are most often associated with diseases such as tuberculosis, other infections, juvenile rheumatoid arthritis, and trauma ${ }^{6}$. Anomalies arising from inappropriately $\mathrm{FCV}$ are collectively called Klippel-Feil syndrome and are classified into three types: I, involving massive fusion of many upper cervical and thoracic vertebrae in blocks; II, involving fusion of only 1 or 2 interspaces, generally $\mathrm{C} 2-\mathrm{C} 3$ or C5-C6; and III, involving cervical and lower or lumbar thoracic fusion ${ }^{12,13}$. Thus, when identifying vertebral synostosis between $\mathrm{C} 5$ and $\mathrm{C} 6$, it is suggested that the referred FCV fits into the type II classification.

The study of the embryological genesis of the spine enables the understanding of many diseases and assists in their diagnosis and treatment. The formation of the spine begins at the end of the third week of embryonic development with formation of the somites; at the end of the fifth week of development, 42 to 44 pairs of somites are present and differ among sclerotomes, which proceed to form vertebrae, intervertebral discs, and ribs ${ }^{13}$. Through metamerism (the process of segmentation of the body) occurring in the embryonic precursor structures of the vertebral column, the vertebrae and their intervertebral discs originate in the form of a chain of segments arranged in sequence to allow the entire structure to arch when the associated muscles are mobilized ${ }^{4}$.

Studies have demonstrated the influence of environmental factors and genetic disorders on the development and segmentation of somites, whether by mutations in genes related to the segmentation pattern of somites (such as the PAX1 gene) or infectious diseases that also induce FCV ${ }^{2,5,14}$; therefore, studies such as those of the present case become valuable tools for understanding the morphofunctional characteristics at the macroscopic level, although the discovery of the exact etiology was limited in the present case due to the availability of only dry bone.

Due to the high incidence rates, as shown in studies of anatomical specimens ${ }^{6,10,15}$, the analysis and detailing of FCV cases, as conducted in the present study, have an immeasurable impact on the training of health professionals; the immersion 
of students in real-world situations of anatomical anomalies in tangible, physical pieces may eventually result in multidisciplinary teams being able to conduct early diagnosis, risk, and therapeutic assessments, which may culminate in improving the quality of life of patients with FCV.

\section{References}

1. Moore KL, Dalley AF. Dorso. In: Moore KL, Dalley AF, eds. Anatomia orientada para a clínica. Rio de Janeiro: Editora Guanabara Koogan; 2019:530-611.

2. Kadadi SP, Mallikarjun M, Jayaprakash BR. A study of fusion of cervical vertebrae- C2 with C3. Int J Biomed Res 2016;7(01):12-15. 3 Borenstein DG. Epidemiology, etiology, diagnostic evaluation, and treatment of low back pain. Curr Rheumatol Rep 2001;13(2):128-134. 4. Standring S. O Dorso. In: Standring S. Gray's Anatomy: A Base Anatômica da Prática Clínica. Rio de Janeiro: Elsevier; 2010:707-748.

5. Kaushal P, Bhukya S. Fusion of C2 and C3: embryological and clinical perspective. Anat J Afr 2018;7(2):1281-1283.

6 Erdil H, Yildiz N, Cimen M. Congenital Fusion of Cervical Vertebrae and Its Clinical Significance. J Anat Soc India 2003;52(2):125-127.

7. Tiwari A, Chandra N, Naresh M, Pandey A, Tiwari K. Congenital abnormal cervical vertebrae - a case report. J Anat Soc India 2002;51:68-69.

8. Besnick D, Niwayama G. Diagnosis of bone and joint disorders. 2nd ed. Philadelphia: WB Saunders; 1985:1081-83.
9. Meschan I. Analysis of roentgen signs in general radiology. Philadelphia: WB Saunders; 1973:618-20.

10. Kulkarni V, Ramesh BR. A spectrum of vertebral synostosis. Journal (JMS) 2012;2(2):71-77.

11. Ravishankar P, Ananthi SK, Radhakrishnan PL, Muthusamy R. Int Arch Integr Med 2015;2(7):127-131.

12. Samartzis DD, Herman J, Lubicky JP, Shen FH. Classification of congenitally fused cervical patterns in Klippel-Feil patients: epidemiology and role in the development of cervical spine-related symptoms. Spine 2006;31(21):798-804.

13. Moore KL, Persaud TVN. Sistema esquelético. In: In: Moore KL, Persaud TVN. Embriologia clínica. Rio de Janeiro: Elsevier; 2008:344381.

14. Yadav Y, Goswami P, Bharihoke V. Cervical Vertebra Synostosis (C2-C3) - A Case Report. Am J Med Case Rep 2014;2(6):120-122.

15. Ajay N, Tejaswi HL, Rajendra R, Makandar UK. Cervical vertebral synostosis: an osteological study. Int J Evid Based Healthc 2015;2(21):3189-3193.

\section{Mini Curriculum and Author's Contribution}

1. Denival Nascimento Vieira Júnior - B.Sc. student. Contribuiton: Effective scientific and intellectual participation for the study, technical procedures, data acquisition; preparation and draft of the manuscript; final approval. ORCID: 0000-00018813-0472.

2. Ardilles Juan Carlos Alves dos Santos - Ph.D. Contribuiton: Design of the study, data interpretation, writing of case report and critical review and final approval. ORCID:0000-0002-5828-0610.

3. Kassia de Oliveira Gomes da Silva - Ph.D. Contribuiton: Design of the study, data interpretation, critical review and final approval. ORCID: 0000-0002-7473-8900.

4. João Antônio Leal de Miranda - Ph.D. Contribuiton: Technical procedures, data interpretation; preparation and draft of the manuscript; critical review and final approval. ORCID: 0000-0002-0273-4169.

5. Katrine Bezerra Cavalcanti - Ph.D. Contribuiton: Guiding professor, responsible for technical procedures, preparation and draft of the manuscript; critical review and final approval. ORCID: 0000-0002-7769-3672.

Received: March 11, 2021

Accepted: April 27, 2021
Corresponding author

Katrine Bezerra Cavalcanti

Email: kbcavalcanti@gmail.com 